\title{
A-770041 reverses paclitaxel and doxorubicin resistance in osteosarcoma cells
}

\author{
Zhenfeng Duan ${ }^{1 *}$, Jianming Zhang ${ }^{2}$, Shunan Ye ${ }^{1}$, Jacson Shen ${ }^{1}$, Edwin Choy ${ }^{1}$, Gregory Cote ${ }^{1}$, David Harmon ${ }^{1}$, \\ Henry Mankin ${ }^{1}$, Yingqi Hua ${ }^{3}$, Yu Zhang ${ }^{4}$, Nathanael S Gray ${ }^{5}$ and Francis J Hornicek ${ }^{1}$
}

\begin{abstract}
Background: Reversing multidrug resistance (MDR) has been an important goal for clinical and investigational oncologists. In the last few decades, significant effort has been made to search for inhibitors to reverse MDR by targeting ATP-binding cassette (ABC) transporters (Pgp, MRP) directly, but these efforts have achieved little clinical success. Protein kinases play important roles in many aspects of tumor cell growth and survival. Combinations of kinase inhibitors and chemotherapeutics have been observed to overcome cancer drug resistance in certain circumstances.

Methods: We screened a kinase specific inhibitor compound library in human osteosarcoma MDR cell lines to identify inhibitors that were capable of reversing chemoresistance to doxorubicin and paclitaxel.

Results: We identified 18 small molecules that significantly increase chemotherapy drug-induced cell death in human osteosarcoma MDR cell lines U-2OS $\mathrm{MR}$ and $\mathrm{KHOSR}_{2}$. We identified A-770041 as one of the most effective MDR reversing agents when combined with doxorubicin or paclitaxel. A-770041 is a potent Src family kinase (Lck and Src) inhibitor. Western blot analysis revealed A-770041 inhibits both Src and Lck activation and expression. Inhibition of Src expression in $\mathrm{U}-2 \mathrm{OS}$ MR and $\mathrm{KHOSR}_{2}$ cell lines using lentiviral shRNA also resulted in increased doxorubicin and paclitaxel drug sensitivity. A-770041 increases the intracellular drug accumulation as demonstrated by calcein AM assay.

Conclusions: These results indicate that small molecule inhibitor A-770041 may function to reverse ABCB1/ Pgp-mediated chemotherapy drug resistance. Combination of Src family kinase inhibitor with regular chemotherapy drug could be clinically effective in MDR osteosarcoma.
\end{abstract}

Keywords: Osteosarcoma, MDR, Src kinase, Doxorubicin

\section{Background}

Osteosarcoma, the most common primary malignant tumor of bone, is typically treated with surgery and adjuvant chemotherapy [1,2]. Chemotherapy usually includes a combination of methotrexate, doxorubicin, and cisplatin. Unfortunately, the efficacy of these agents is hampered by the eventual development of multidrug resistance (MDR). This plateau in terms of overall survival has been present for a few decades without change. Almost one third of patients with localized osteosarcoma experience recurrent or progressive disease (usually caused by drug resistance)

\footnotetext{
*Correspondence: zduan@mgh.harvard.edu

${ }^{1}$ Center for Sarcoma and Connective Tissue Oncology, Massachusetts General Hospital, 100 Blossom St., Jackson 1115, Boston 02114, MA, USA

Full list of author information is available at the end of the article
}

and the average survival period after a recurrence are about one year [1-3]. Therefore, overcoming MDR has been a high priority for both clinical and investigational oncologists [4-6]. Unfortunately, the mechanism of acquiring MDR in osteosarcoma is not well understood. A variety of mechanisms, including overexpression of the $\mathrm{ABC}$ drug efflux pumps P-glycoprotein (Pgp), and elevation of the apoptotic threshold that contributes to drug resistance [5,7-12], have been proposed to play important roles for cancers acquiring MDR. Targeting multidrug resistance is one of the biggest challenges for successful treatment of osteosarcoma.

The human kinome contains approximately 600-protein kinases that mediate phosphorylation of proteins at an estimated 250,000 sites [13,14]. Multiple lines of evidence

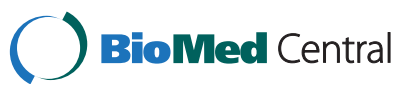

(c) 2014 Duan et al.; licensee BioMed Central Ltd. This is an Open Access article distributed under the terms of the Creative Commons Attribution License (http://creativecommons.org/licenses/by/4.0), which permits unrestricted use, distribution, and reproduction in any medium, provided the original work is properly credited. The Creative Commons Public Domain Dedication waiver (http://creativecommons.org/publicdomain/zero/1.0/) applies to the data made available in this article, unless otherwise stated. 
indicate cross-talk between kinase mediated signaling pathways and multidrug resistant in different cancers. Several kinases such as IGF-1R, PI3K/AKT, PDGFR, mTOR and Src have been found to be highly expressed in different osteosarcomas, particularly in the late stage of the development of drug resistant tumor [15-17]. Inhibition of AKT enhances the cytotoxic effects of both paclitaxel and doxorubicin in tumor model systems [18]. Small interfering RNA (siRNA) downregulation of IGF-IR expression in MDR osteosarcoma cell lines also causes resensitization to doxorubicin $[19,20]$. It has been shown that suppression of several kinases, such as PI3K/AKT/mTOR, Src, IGF-R, EGFR, JIK, Jak, or MEK/ERK significantly enhance cell death in the presence of low concentrations of chemotherapeutic drug, suggesting the potential utility of these kinases as drug targets $[5,13,15,19,21]$. Recently, some kinase inhibitors have also been found to reverse MDR by inhibiting the function of $A B C$ transporters, including Pgp or MRP, or enhancing the efficacy of conventional chemotherapeutic drugs induced apoptosis [22,23].

Based on these observations, it is anticipated that kinases represent a class of potential therapeutic targets in chemotherapy resistant osteosarcoma. We hypothesized that inhibiting of the expression and activation of certain kinases may enhance the efficacy of chemotherapy and/or reverse MDR. In order to identify the most suitable kinase candidates as therapeutic targets in drug resistant osteosarcoma patients, we screened a well-annotated kinase inhibitor focused library comprised of 3,000 commercially available known kinase inhibitors, as well as novel, ATP competitive kinase inhibitors targeting either active or inactive kinase conformations [24]. We systematically evaluated the potential reversal of MDR by the identified agent A-770041 and further studied the underlying mechanisms.

\section{Methods}

\section{Kinase inhibitor library}

We assembled a library of approximately 3000 diverse inhibitors and screened a subset of the library for kinomewide selectivity profiling using binding (KinomeScan) [25], enzymatic (SelectScreen, Invitrogen Carlsbad, CA) and chemical proteomic approaches (Kinativ) [26]. This library is comprised of 500 commercially available known kinase inhibitors, as well as novel ATP competitive kinase inhibitors targeting either active or inactive kinase conformations. These compounds are characterized as being relatively potent and selective toward a relatively narrow array of kinase targets. This library was then screened against a number of different cancer cell lines or cells engineered to be associated with a defined oncogene (BRFV600E, KRAS, c-Myc, etc.) [27,28].

\section{Human osteosarcoma cell lines}

The multidrug resistant $\mathrm{U}-2 \mathrm{OS}_{\mathrm{MR}}$ (established by selection against doxorubicin) and $\mathrm{U}-2 \mathrm{OS}_{\mathrm{TR}}$ (established by selection against taxol/paclitaxel) was established in our laboratory as previously reported [20,23]. The multidrug resistant $\mathrm{KHOS}_{\mathrm{R} 2}$ (established by selection with doxorubicin) cell line was kindly provided by Dr. Efstathios Gonos (Institute of Biological Research and Biotechnology, Athens, Greece) [29]. These cell lines were cultured in RPMI 1640 (Invitrogen, CA) supplemented with 10\% FBS, 100 units $/ \mathrm{mL}$ penicillin, and $100 \mu \mathrm{g} / \mathrm{mL}$ streptomycin (Invitrogen). Cells were incubated at $37^{\circ} \mathrm{C}$ in $5 \% \mathrm{CO}_{2}-95 \%$ air atmosphere and passaged when near-confluent monolayers were achieved using trypsin-EDTA solution. Drug resistant cell lines were periodically cultured in the respective drug to confirm their drug resistance characteristics. Cells were free from Mycoplasma contamination as tested using the MycoAlert Mycoplasma Detection Kit from Cambrex (East Rutherford, NJ).

\section{Drugs}

Doxorubicin and paclitaxel were provided by the pharmacy at the Massachusetts General Hospital Cancer Center. The stock solutions of drugs were prepared according to the manufacturer's specifications and stored at $-20^{\circ} \mathrm{C}$.

\section{Screening kinase inhibitor focused library}

We screened the kinase specific compound library in human osteosarcoma MDR cell lines $\mathrm{U}-2 \mathrm{OS}_{\mathrm{MR}}$ and $\mathrm{KHOS}_{\mathrm{R} 2}$ to determine the role of kinases in supporting chemoresistance to doxorubicin and paclitaxel in these MDR cells. The kinase inhibitor screening was performed at the concentration of $0.66 \mu \mathrm{M}$ and $1.8 \mu \mathrm{M}$ with or without the presence of paclitaxel $(0.1 \mu \mathrm{M})$, doxorubicin $(0.5 \mu \mathrm{M})$ in a four-day cellular proliferation assay (Figure 1). The combinatory drug effect was measured via CellTiter-Glo ${ }^{\circ}$ Luminescent Cell Viability Assay Kit (Promega, Madison, WI) for automated high-throughput screening (HTS), cell proliferation and cytotoxicity assays.

\section{MTT cell proliferation assay}

Drug cytotoxicity was assessed in vitro using the MTT assay as previously described $[15,23]$. Briefly, $2 \times 10^{3}$ cells per well were plated in 96-well plates in culture medium (RPMI 1640 supplemented with 10\% FBS and penicillin/ streptomycin) containing increasing concentrations of either A-770041, doxorubicin, paclitaxel alone or in combination with both. After $96 \mathrm{~h}$ of culture, $20 \mu \mathrm{L}$ of MTT ( $5 \mathrm{mg} / \mathrm{mL}$ in PBS, purchased from Sigma) were added to each well and the plates were incubated for $4 \mathrm{~h}$. The resulting formazan product was dissolved with acid (HCL)-isopropanol and the absorbance at a wavelength of $490 \mathrm{~nm}$ (A490) was read on a SPECTRAmax Microplate Spectrophotometer (Molecular Devices). Experiments were done in triplicate. Dose-response 


\section{Kinase inhibitor focused compound library}

\section{Compound alone \\ Compound $+0.1 \mu \mathrm{M}$ Paclitaxel \\ Compound + 0.5 $\mu \mathrm{M}$ Doxorubicin}

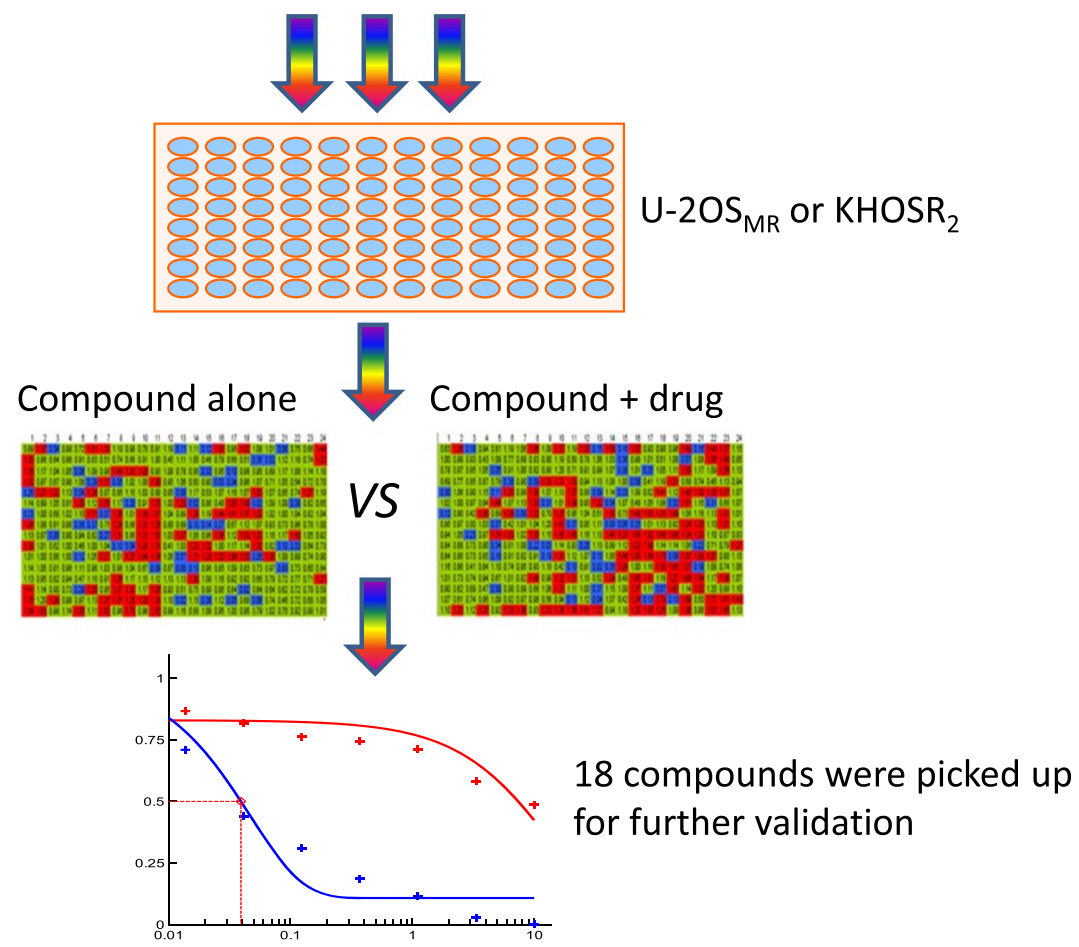

Figure 1 Strategy for screening a kinase specific compound library in multidrug resistant osteosarcoma cell lines. The kinase inhibitor screening was performed at the concentration of $0.66 \mu \mathrm{M}$ and $1.8 \mu \mathrm{M}$ with or without the presence of paclitaxel $(0.1 \mu \mathrm{M})$ or doxorubicin $(0.5 \mu \mathrm{M})$ in a four-day cellular proliferation assay. The combinatory drug effect was measured via CellTiter-Glo ${ }^{\oplus}$ Luminescent Cell Viability Assay Kit as described in Methods. Red: no effect on drug sensitivities; green: minor effect on drug sensitivities; blue: significant effect on drug sensitivities.

curves were fitted using GraphPad PRISM 4 software (GraphPad Software).

\section{Lentiviral Src kinase shRNA transduction}

The effect of Src kinase knockdown on drug sensitivity in osteosarcoma MDR cell lines U-2OS was examined using MISSION $^{\circ}$ LentiExpress $^{\mathrm{Tw}}$ human Src kinases shRNA (Sigma, St Louis, MO, TRC number: TRCN0000038149, Target sequence: 5' -GCTCGGCTCA TTGAAGACAAT $-3 "$ ). Transduction was carried out by following the manufacturer's protocol as previously described [30]. In brief, on day $1, \mathrm{U}-2 \mathrm{OS}_{\mathrm{MR}}$ or $\mathrm{KHOS}_{\mathrm{R} 2}$ cells were diluted to $2 \times 10^{4} \mathrm{cells} / \mathrm{ml}$ in complete medium. Polybrene (hexadimethrine bromide) was added to a final concentration of $11.3 \mu \mathrm{g} / \mathrm{ml}$ and then $90 \mu \mathrm{l}$ of cell suspension was added to each well of a 96-well plate following by add $10 \mu \mathrm{l}$ of Src kinases shRNA lentivirus solution and incubated overnight. On day 2 , the media was gently aspirated and $100 \mu \mathrm{l}$ of complete media with different concentrations of paclitaxel or doxorubicin were replaced in each well. On day 5 , the number of viable cells was determined by MTT assay as described above.

\section{Western blotting}

The human phosphorylated Lck (pLck), pSrc, pAKT (threonine [Thr]308), pmTOR, CDK11, survivin, and BcL- $\mathrm{X}_{\mathrm{L}}$ antibodies were purchased from Cell Signaling Technologies (Dedham, MA). The Pgp monoclonal antibody C219 was purchased from Covance Inc. (Formerly Signet, Dedham, MA). The mouse monoclonal antibody to human actin was purchased from Sigma-Aldrich (St. Louis, MO). Western blot analysis was performed as previously described with modifications [30]. Briefly, the cells were lysed in $1 \mathrm{X}$ radioimmunoprecipitation assay (RIPA) lysis buffer (Upstate Biotechnology, Lake Placid, NY), and protein concentration was determined by the DC Protein Assay (Bio-Rad, Hercules, CA) with a spectrophotometer (Beckman DU-640, Beckman Instruments, Inc.). Total protein $(25 \mu \mathrm{g})$ was resolved on NuPage $4 \%$ to $12 \%$ Bis-Tris gels (Invitrogen). After electrophoresis, proteins 
were transferred to PROTRAN ${ }^{\circ}$ nitrocellulose transfer membranes (Whatman GmbH, Germany). Membranes were blocked for 2 hours at $4^{\circ} \mathrm{C}$ with Odyssey Blocking Buffer (LI-COR Biosciences, Lincoln, NE), then incubated at $4{ }^{\circ} \mathrm{C}$ overnight with primary antibodies diluted in Odyssey Blocking Buffer. After incubating with primary antibodies, the membranes were washed with TBS-T (containing 0.1\% Tween 20) three times for 5 minutes. The membranes were then incubated with IRDye800CW-conjugated goat antirabbit IgG or IRDye680-conjugated goat anti-mouse IgG secondary antibodies (LI-COR Biosciences) diluted in Odyssey Blocking Buffer for 1 hour at room temperature with shaking. The blots were then washed three times with TBS-T and rinsed again with PBS. The levels of expressed proteins were visualized by scanning the membrane on an Odyssey Infrared Imaging System (LI-COR Biosciences) with both 680- and 800-nm channels.

\section{Apoptosis assay}

Apoptosis was evaluated by a caspase-cleaved keratin 18 based quantification kit, the M30-Apoptosense ELISA assay, as per manufacturer's instructions (Peviva $A B$, Bromma, Sweden). The ELISA apoptosis detects a 21-kDa fragment of cytokeratin 18 that is only revealed after caspase cleavage of the protein. Osteosarcoma MDR cells of $\mathrm{U}-2 \mathrm{OS}_{\mathrm{MR}}$ and $\mathrm{KHOS}_{\mathrm{R} 2}$ were seeded at $8 \times 10^{3}$ cells/per well in a 96-well plate for 24 hours before being treated with $0.1 \mu \mathrm{M}$ doxorubicin plus different concentrations of A-770041 for 48 hours. The cells were then lysed by adding $10 \mu \mathrm{l} 10 \% \mathrm{NP}-40$ per well, and the manufacturer's instructions for the apoptosis assay were followed. Apoptosis was also evaluated by Western blot using whole-cell lysates immunoblotted with specific antibodies to PARP (Cell Signaling Technologies) and its cleavage products.

\section{Intracellular accumulation of calcein AM}

Osteosarcoma MDR cells of $\mathrm{KHOS}_{\mathrm{R} 2}$ were plated onto 96-well plates at a density of $4 \times 10^{3}$ cells/well in a volume of $100 \mu \mathrm{l}$ RPMI1640 medium and grown for $24 \mathrm{~h}$. Different concentrations $(0,0.1,0.5$ and $1 \mu \mathrm{M})$ of A-770041 were added for one hour. Calcein AM (Invitrogen) was diluted to $1 \mu \mathrm{M}$ in culture medium, and then $50 \mu \mathrm{l}$ of calcein $\mathrm{AM}$ was added to each microplate well containing $100 \mu \mathrm{l}$ of the culture medium. After 30 minutes of exposure to calcein $A M$ at $37^{\circ} \mathrm{C}$, the medium was removed by aspiration, and cells were counterstained with Hoechst $33342(1 \mu \mathrm{g} / \mathrm{ml}$ in culture medium) for $2 \mathrm{~min}$. The intracellular accumulation of calcein AM was then visualized and quantified on a Nikon Eclipse Ti-U fluorescence microscope equipped with a SPOT RT digital camera.

\section{Statistical analysis}

Statistical analyses were performed using the GraphPad PRISM5 software from GraphPad Software, Inc (San
Diego, CA, USA). The student $t$ test was used to analyze the differences between two groups. Results are expressed as mean $\pm \mathrm{SD}$ and $\mathrm{P}<0.05$ was considered statistically significant.

\section{Results \\ Identification of kinase inhibitors that reverse drug resistance in osteosarcoma MDR cell lines}

After screening 3,000 compounds from a preselected, kinase-based small molecule library, we identified 18 small molecule compounds that can significantly increase chemotherapy drug-induced cell death in human osteosarcoma cell lines U-2OS $\mathrm{MR}$ and $\mathrm{KHOS}_{\mathrm{R} 2}$ (Additional file 1: Table S1). Several previously reported kinase inhibitors such as dasatinib, AP25434, GSK461364, GP74514A and JNK-IN-X were also on the list of 18 small molecule compounds. We further verified efficacy of those 18 lead compounds by serially titrating drug combination studies with doxorubicin and paclitaxel. Eight of them showed improved $\mathrm{IC}_{50}$ in combination with doxorubicin or paclitaxel. These 8 small molecule compounds include inhibitors targeting multiple pan-tyrosine kinases such as Src family kinase (A-770041), kinases in cell cycle regulations such as PLK1 (GSK461364), CDK (GP74514A), and kinases in cell stress responses such as JNK (JNK-IN-X). Further studies validated A-770041, a compound previously reported as a highly potent pan-Src family kinase inhibitor [31-33], as the top one of the most effective MDR reversing agents when used in combination with doxorubicin or paclitaxel, as determined by drug sensitivity assays. Because of their target specificity and wide range coverage of the human kinome, the kinase inhibitor focused library compounds were anticipated to be useful to more easily identify the kinase mediators of cancer cell survival associated signaling that could be exploited for the purpose of drug development. Identified drug candidates could ideally provide further insight into the mechanism(s) involved in cancer MDR development, and at the same time potentially aid in developing and optimizing novel small molecule inhibitors able to overcome drug resistance and kill cancer cells more effectively.

\section{Structure of A-770041 and its activities reversing drug resistance}

A-770041 was reported as an inhibitor Lck, a Src-family kinase expressed in lymphocytes [31,32]. We examined the effect of A-770041 on increasing the chemotherapy sensitivities of osteosarcoma MDR cell lines. After exposing the U-2OS ${ }_{\mathrm{MR}}$ or $\mathrm{KHOS}_{\mathrm{R} 2}$ cell lines to paclitaxel, doxorubicin, or A-770041 alone, or the combination of paclitaxel or doxorubicin with A-770041 in complete cell culture medium for 96 hours, the relative numbers of viable cells were determined by MTT assay. Incubation of both $\mathrm{U}-2 \mathrm{OS}_{\mathrm{MR}}$ and $\mathrm{KHOS}_{\mathrm{R} 2}$ cell lines with nonlethal 
concentrations of A-770041 $(0.5 \mu \mathrm{M})$ was found to increase paclitaxel and doxorubicin drug sensitivities and reverse drug resistance (Figure 2).

\section{Effects on drug sensitivities from inhibiting Src expression by shRNA}

A-770041 is known as a Src-family kinase inhibitor. To evaluate the contribution of Src mRNA expression levels to drug resistance in osteosarcoma MDR cell lines, the Src expression in $\mathrm{U}-2 \mathrm{OS}_{\mathrm{MR}}$ or $\mathrm{KHOS}_{\mathrm{R} 2}$ cells was inhibited by using lentiviral Src kinase shRNA. The relative paclitaxel or doxorubicin sensitivities were determined by MTT in Src shRNA-transduced and in control MDR cell lines. Cytotoxicity was measured 96 hours after transduction with Src shRNA and treatment with paclitaxel or doxorubicin (see Methods). The results showed that Src down-regulation by shRNA partially recovered sensitivity to paclitaxel and doxorubicin (Figure $2 \mathrm{~B}$ and Figure $2 \mathrm{C}$ ).

A-770041 is synergistic with paclitaxel and doxorubicin in $\mathrm{KHOS}_{\mathrm{R} 2}$ cell lines with $\mathrm{ABCB1/Pgp}$ overexpression

The potential reversal of MDR by A-770041 was further evaluated in $\mathrm{KHOS}_{\mathrm{R} 2}$ cell lines with defined overexpression of the major MDR transporter ABCB1/Pgp. This MDR osteosarcoma cell line is remarkably resistant to the corresponding transporter substrate anticancer drugs including paclitaxel and doxorubicin. Subsequently, the synergistic effects of combinations of A-770041 with paclitaxel or doxorubicin in different ratios were evaluated in $\mathrm{KHOS}_{\mathrm{R} 2}$ cell lines. Synergistic cytotoxic effects were found in combinations of A-770041 with paclitaxel or doxorubicin in $\mathrm{KHOS}_{\mathrm{R} 2} \mathrm{MDR}$ cell lines (Figure 3). The sensitivity to A-770041 was also tested in a panel of non MDR osteosarcoma cell lines including U-2OS, KHOS, SaoS, MG63 cell lines. A-770041 alone was found to exhibit similar anticancer activity in these drug sensitive cell lines as in drug resistant $\mathrm{U}-2 \mathrm{OS}_{\mathrm{MR}}$ or $\mathrm{KHOS}_{\mathrm{R} 2}$ cell lines (data not shown).

\section{Effect of A-770041 on the expression and activation of Src, Lck}

Src kinase expression and activation has been shown as the primary pathway involved in the malignant osteosarcoma phenotype $[34,35]$. The effects of A-770041 on the expression of pSrc, pLck, pAKT and other kinases or apoptotic proteins in osteosarcoma MDR cell lines were analyzed by Western blot. The U-2OS $\mathrm{MR}, \mathrm{KHOS}_{\mathrm{R} 2}$ or $\mathrm{U}-2 \mathrm{OS}_{\mathrm{TR}}$ cell lines were incubated either with a range of concentrations $(0,0.3$ or $1 \mu \mathrm{M})$ of A-770041 for 48 hours. Western blot analysis revealed that A-770041 inhibits both Src and Lck activation and expression in osteosarcoma MDR cells, but has less or no effect on other kinases such as pAKT, pmTOR or CDK11 (Figure 4). Treatment with A-770041 also decreased expression of the antiapoptotic proteins survivin and $\mathrm{Bcl}-\mathrm{X}_{\mathrm{L}}$ in the $\mathrm{U}-2 \mathrm{OS}_{\mathrm{MR}}$ cell line (Figure 4).

A<smiles>COC1CC(C2NN(C3CCC(N4CCN(C(C)O)CC4)CC3)C3NCNC(N)C23)CCC1C(O)NC1CC2CCCCC2N1C</smiles>
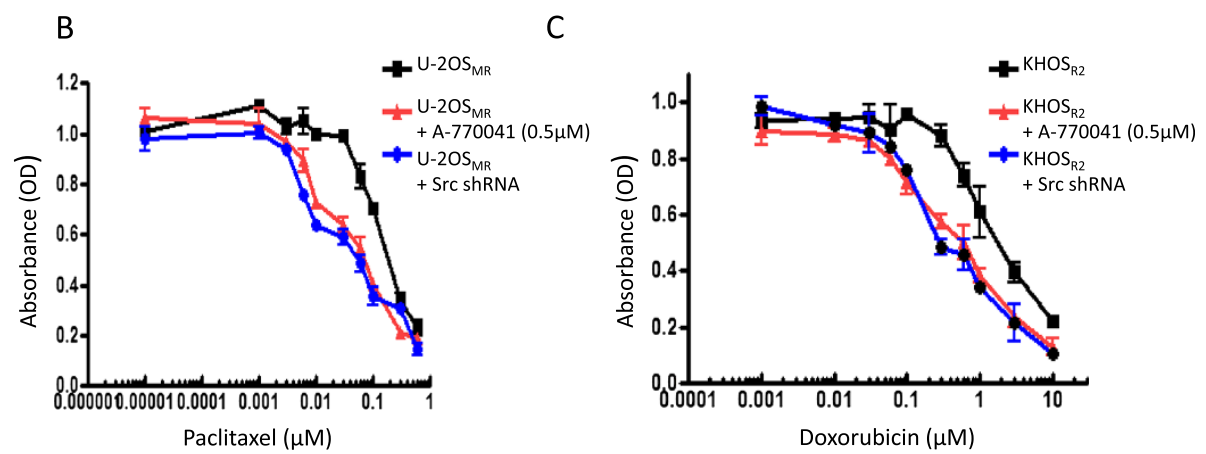

Figure 2 A-770041 or Src shRNA reverses drug resistance. (A) Structure of A-770041. (B) A-770041 or Src lentiviral shRNA reverse paclitaxel resistance inU-2OS $\mathrm{MR}_{\mathrm{R}}$ cell line. (C) A-770041 or Src lentiviral shRNA reverse doxorubicin resistance in $\mathrm{KHOS}_{\mathrm{R} 2}$ cell line. Results are expressed as mean \pm standard deviations (SD). 


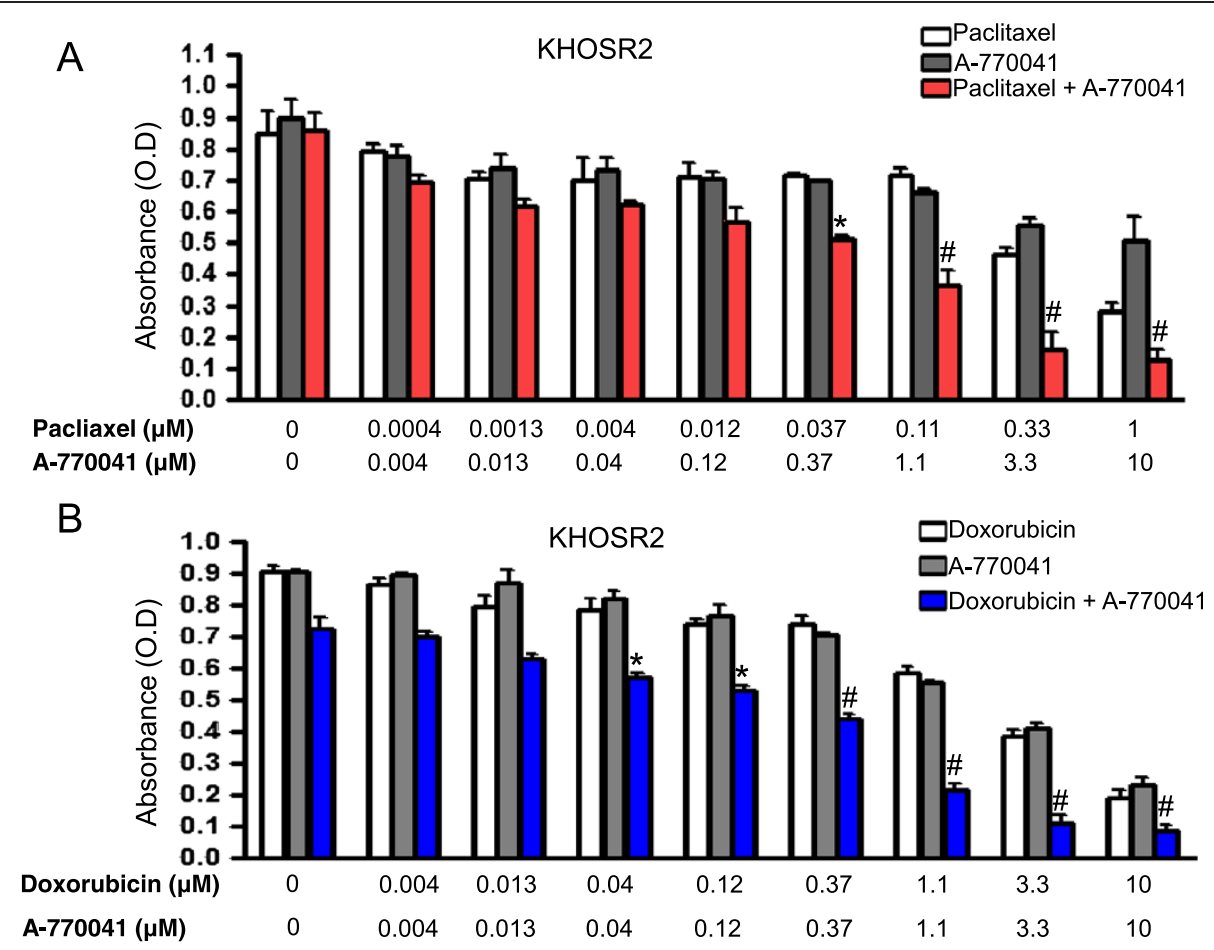

Figure 3 Synergistic effect of A-770041 with paclitaxel or doxorubicin in drug resistant cell line. The KHOS ${ }_{R 2}$ cells were cultured in the presence of varying concentrations of either paclitaxel $(0.0004-1 \mu \mathrm{M}, \mathbf{A})$ or doxorubicin $(0.004-10 \mu \mathrm{M}, \mathbf{B})$ alone or in combination with A-770041 $(0.004-10 \mu \mathrm{M})$ in regular RPMI1640 medium for 96 hours. The inhibition of cell growth was determined by MTT assay. The results are shown as the mean value of triplicate samples and are representative of 3 independent experiments. The student $t$ test was used to analyze the differences between two groups. ${ }^{*} P<0.01$ vs. paclitaxel or A-770041 treated cells alone, $\# P<0.001$ vs. paclitaxel or A-770041 treated cells alone.

A-770041 induced apoptosis contributes to the reversal of Pgp-mediated paclitaxel and doxorubicin resistance

Since the combination of A-770041 with paclitaxel or doxorubicin is highly synergistic (Figure 3), we also investigated whether A-770041 possesses properties other than Pgp inhibition to reverse Pgp-mediated resistance. The $\mathrm{U}-2 \mathrm{OS}_{\mathrm{MR}}$ or $\mathrm{KHOS}_{\mathrm{R} 2}$ cell lines were treated with a combination of low concentration of doxorubicin $(0.1 \mu \mathrm{M})$ and A-770041 $(0.3 \mu \mathrm{M}, 1 \mu \mathrm{M})$ for 48 hours, after which the extent of apoptosis was measured. While doxorubicin only led to insignificant apoptosis at this low concentration, its combination with A-770041 was found to dramatically increase the apoptosis in the resistant U-2OS $\mathrm{MR}$ or $\mathrm{KHOS}_{\mathrm{R} 2}$ cells as demonstrated by M30-Apoptosense ELISA assay (Figure 5A). The effect of A-770041 on the induction of apoptosis was further investigated by immunoblotting for PARP cleavage. PARP cleavage was detected after the treatment of $U-2 \mathrm{OS}_{\mathrm{MR}}$ or $\mathrm{KHOS}_{\mathrm{R} 2}$ cells with A-770041 in combination with doxorubicin (Figure 5B). In addition to PARP cleavage assay, quantification of apoptosis was also evaluated by checking Caspase-3/7 activations. Compared with cells treated with doxorubicin alone, the combination of A-770041 resulted in greater levels of apoptosis in these osteosarcoma MDR cell lines (data not shown). The reversal of Pgp-mediated drug resistance by A-770041 may also be associated with alteration of the transporter expression. Therefore, protein expression of Pgp was examined in $\mathrm{U}-2 \mathrm{OS}_{\mathrm{MR}}$, $\mathrm{KHOS}_{\mathrm{R} 2}$ and U-2OS $\mathrm{TR}$ cells. After incubating the cells with A-770041 at concentrations up to $1 \mu \mathrm{M}$ for 48 hours, A-770041 did not alter the expression of Pgp protein levels (Figure 5B).

\section{A-770041 modulates Pgp-mediated uptake and efflux of calcein AM}

Reversing Pgp-mediated MDR will result in an intracellular accumulation of chemotherapeutics, which can be achieved by inhibiting Pgp function. Therefore, we examined the effect of A-770041 on the uptake and efflux of Calcein AM, a substrate of Pgp in $\mathrm{KHOS}_{\mathrm{R} 2}$. Pgp inhibition can be directly correlated with the amount of intracellular Calcein AM fluorescence. A-770041 was shown to increase intracellular accumulation of Calcein in osteosarcoma MDR cell line $\mathrm{KHOS}_{\mathrm{R} 2}$ in a dose-dependent manner as determined by image analysis (Figure 6). A-770041 had a prominent effect on the accumulation of Calcein in $\mathrm{KHOS}_{\mathrm{R} 2}$ cells at a concentration as low as $0.01 \mu \mathrm{M}$. In the control parental drug-sensitive cell lines U-2OS and KHOS, which do not overexpress Pgp, A-770041 had no evident effect on accumulation of Calcein (data not shown). 


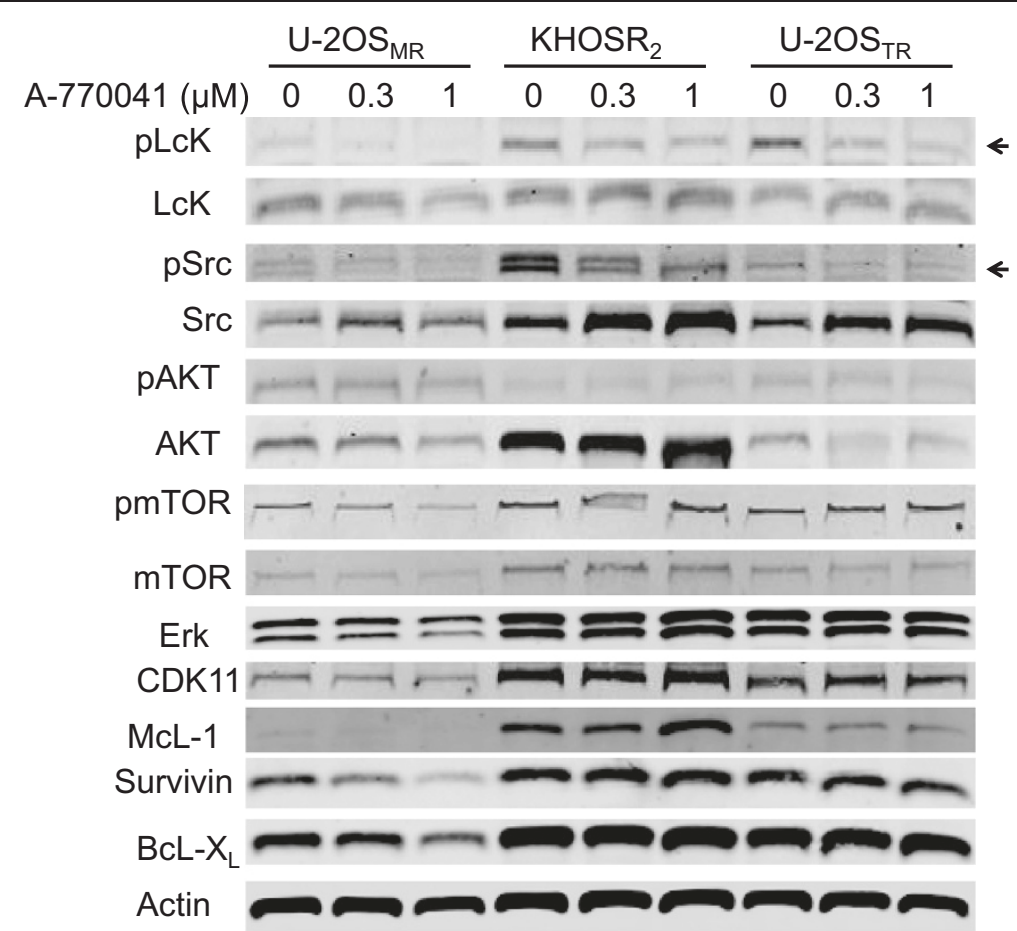

Figure 4 A-770041 inhibits Src and Lck expression in drug-resistant osteosarcoma cells in a dose-dependent manner. $U-2 O S_{M R}, K H O S_{R 2}$ or U-20S $S_{\text {TR }}$ cells were treated with A-770041 $(0,0.3$, or $1 \mu \mathrm{M})$ in regular RPMI1640 medium for 48 hours. Total cellular proteins were subjected to Western blotting with specific antibodies as described in Methods. The levels of expressed proteins were visualized by scanning the membrane on an Odyssey Infrared Imaging System. Arrows indicate the confirmation of A-770041 inhibits both Src and Lck activation and expression as determined by densitometric analysis of Western blot results.

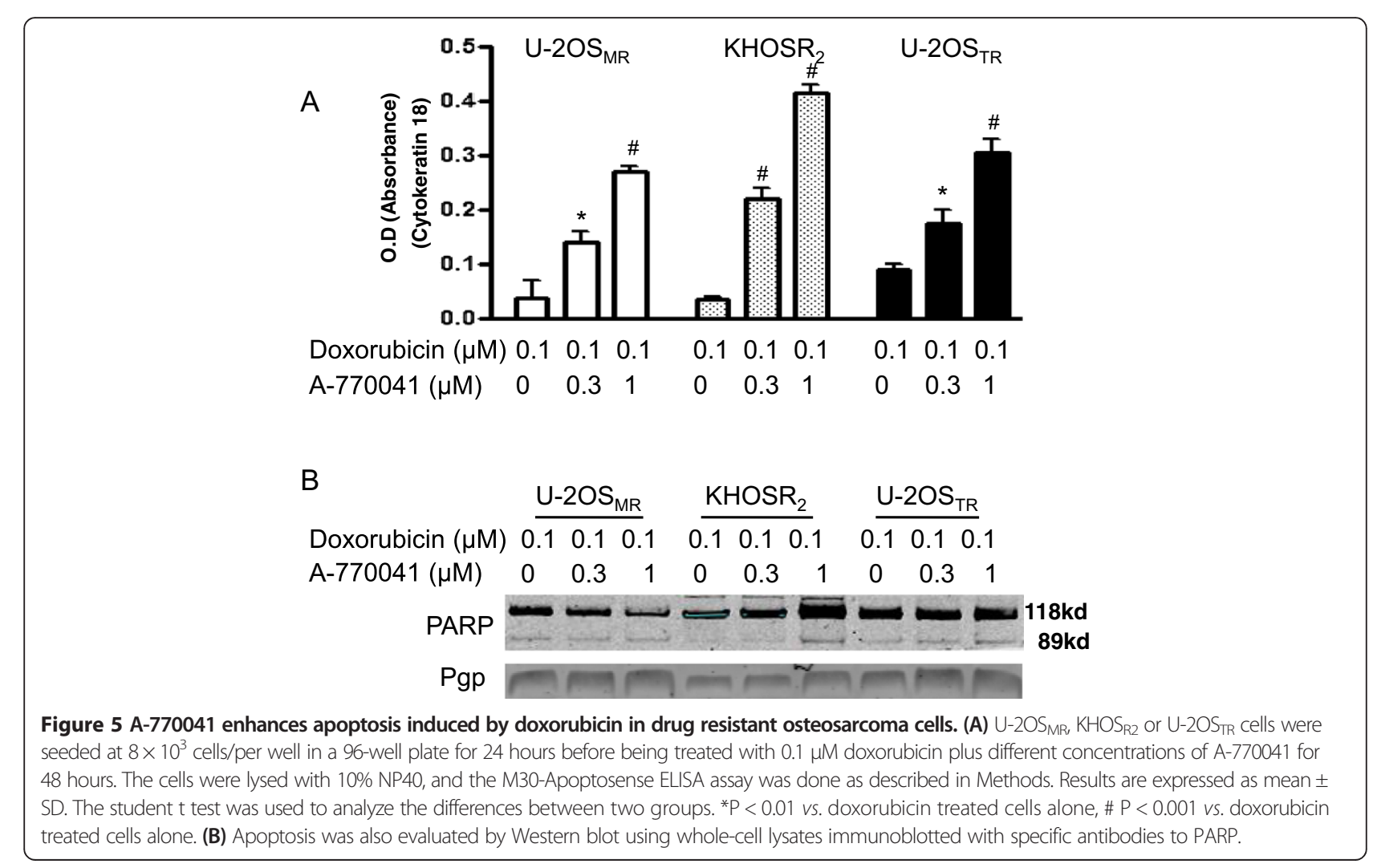




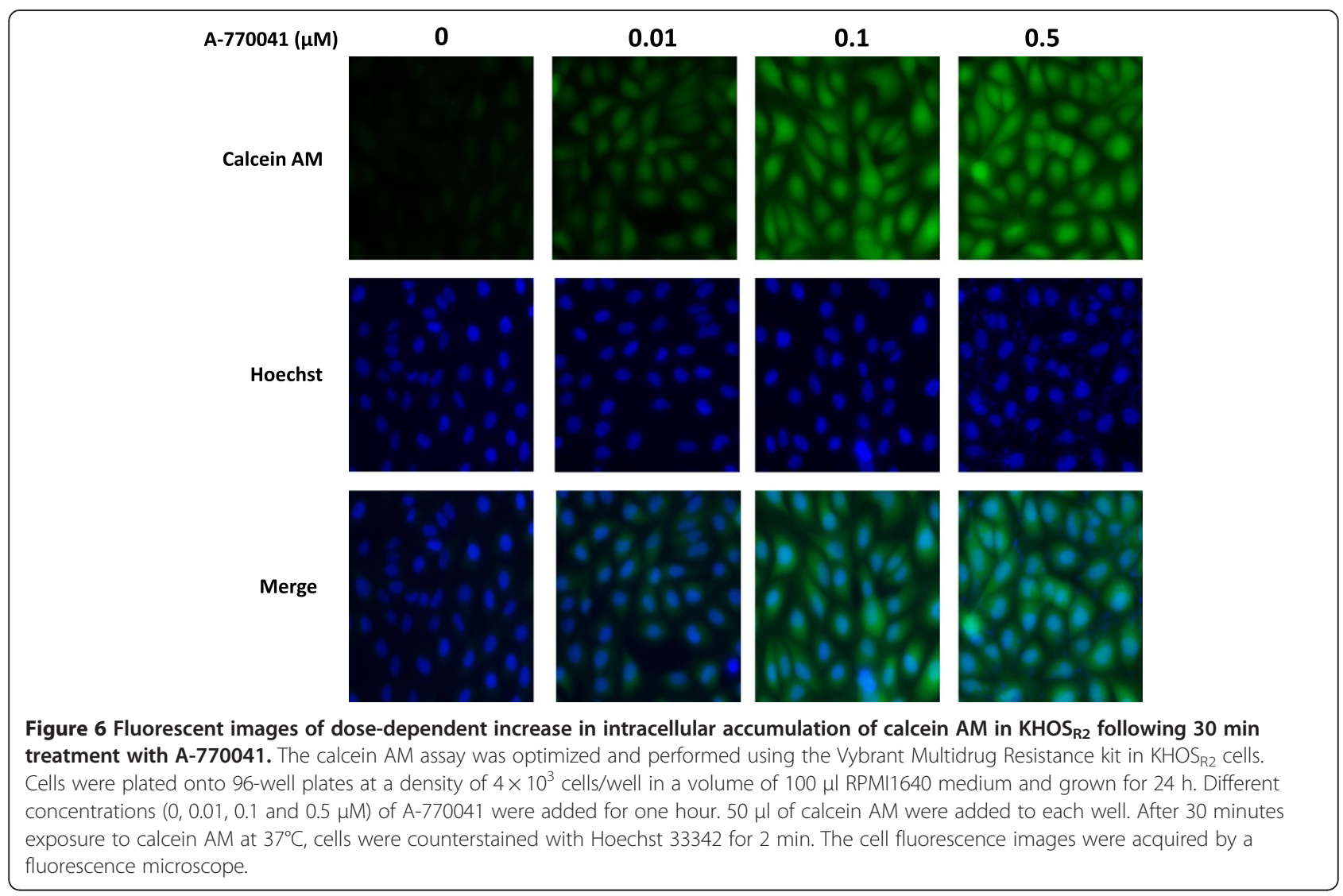

\section{Discussion}

Protein kinases play important roles in the many aspects of cancer including in maintaining or supporting the drug resistance phenotype $[13,22,23]$. Overexpression and activation of specific kinases have been associated with progressive drug resistance. Several recent reports have demonstrated that some kinase inhibitors or other agents are also potent inhibitors of Pgp or MRP transporters and thereby increase drug sensitivities [22,23,36-39]. Synergistic cytotoxic effects of inorganic phosphate and chemotherapeutic drugs on human osteosarcoma cells have been reported recently $[38,39]$. Small molecular compounds capable of inhibiting specific kinases and Pgp represent a desirable approach for overcoming Pgp-mediated drug resistance in human cancer. In this study, we report that A-770041, a known Src family kinase inhibitor originally developed as an immunosuppressant to prevent acute graft rejection [31-33], is a novel MDR reversing agent whose mechanism of action includes both the inhibition of Src and Lck activation and expression, and the inhibition of Pgp function by increases the intracellular drug accumulation.

Cell-based screening of a preselected kinase-based small molecule compound library identified A-770041 as one of the most effective drug resistance reversing agents in two osteosarcoma MDR cell line models, $\mathrm{U}-2 \mathrm{OS}_{\mathrm{MR}}$ and
$\mathrm{KHOS}_{\mathrm{R} 2}$, having defined overexpression of the major MDR transporters, ABCB1/Pgp. These osteosarcoma resistant cell lines have been extensively characterized with stable MDR phenotype in previous studies $[6,7,20,29]$. MTT assay showed A-770041 significantly overcomes drug resistance in both $\mathrm{U}-2 \mathrm{OS}_{\mathrm{MR}}$ and $\mathrm{KHOS}_{\mathrm{R} 2}$ MDR cell lines. Knockdown of Src with lentiviral shRNA also increased drug sensitivity to transporter substrate anticancer drugs paclitaxel and doxorubicin, suggesting that blocking the Src pathway might overcome MDR in osteosarcoma. We then evaluated A-770041's potential synergistic cytotoxic effect when used in combination with paclitaxel and doxorubicin. The data showed that A-770041 is highly synergistic with both paclitaxel and doxorubicin in these MDR cell lines. As demonstrated by Western analysis, part of these effects was potentially through decreased expression of Src and Lck.

$\mathrm{Src}$ is a nonreceptor tyrosine kinase encoded by the Src proto-oncogene. It is one of the eight members (Src, Fyn, Yes, Lck, Lyn, Hck, Fgr and Blk) of the Src family of kinases. Both overexpression and overactivation of Src have been shown to aid in the development of osteosarcoma by promoting key oncogenic mechanisms such as cell proliferation, adhesion, invasion, and resistance to apoptosis induced by chemotherapy drugs $[34,40,41]$. Src kinase activity is regulated via a variety of receptor and non- 
receptor tyrosine kinases such as EGFR, PDGF, and Jak. Activation of Src kinase leads in turn to activation of a variety of downstream signaling pathways such as the Ras/ MAPK pathway, and activation of the Stat3, resulting in cell cycle progression from G2 to M phase and VEGF production, which aids in angiogenesis and tumor growth and invasion. Src is highly expressed and activated in sarcomas of diverse subtypes, including high-grade osteosarcoma, leiomyosarcoma, synovial sarcoma and liposarcoma $[34,40]$. The Src inhibitor dasatinib (BMS-354825) induces apoptosis in osteosarcoma cells [35]. A more recent study showed treatment of synovial sarcoma cells with dasatinib also led to apoptosis, decreased proliferation, and was associated with reduced phosphorylation of IGF-1R, AKT and Stat3. Furthermore, combination treatment with dasatinib and chemotherapeutic agents results in additive effects [40]. Inhibition of Src protein expression by small interfering RNA also induced apoptosis [35]. Inhibition of Src and its downstream signaling pathways has been shown to inhibit growth, migration, and invasion of a variety of human cancer cells including osteosarcoma [35,42]. It has been shown that inhibition of Src, either pharmacologically by Src inhibitor or through expression of a Src dominant-negative fusion construct, increased the cytotoxicity of paclitaxel or cisplatin, in both mouse and human cancer cells [21,40,42]. Importantly, Src inhibition has also been shown to reverse drug resistance in ovarian cancer MDR cells [42]. Cytotoxicity in response to Src inhibition was associated with enhanced apoptosis in these studies. Consistent with these findings, A-770041 also increased the apoptosis induced by doxorubicin in osteosarcoma MDR cell lines. The synergistic activity of A-770041 with doxorubicin suggests that A-770041 could induce apoptosis in doxorubicin-resistant cells through mechanisms independent of inhibition of Pgp.

The interaction of kinase inhibitor with ABC transporter Pgp has been documented in several studies. For example, gefitinib (Iressa), a selective EGFR tyrosine kinase inhibitor, is used for the treatment of lung cancer. It has been found that clinically achievable levels of gefitinib moderately reversed the Pgp-mediated resistance to paclitaxel and docetaxel in Pgp overexpressing cells [43]. Gefitinib increased the intracellular accumulation of the Pgp substrate rhodamine-123 in resistant cells, and activated ATPase in a preparation of pure Pgp-expressing membrane $[43,44]$. These findings suggest that gefitinib may directly interact with Pgp and inhibit its function. Our current study showed A-770041 significantly increases intracellular accumulation of calcein in osteosarcoma MDR cell line $\mathrm{KHOS}_{\mathrm{R} 2}$ in a dose-dependent manner. These results indicated that A-770041 can also inhibit Pgp efflux function via interaction with Pgp. Drugs interacting with MDR transporter proteins like Pgp may be useful not only for the reversal of cancer drug resistance, but also for increasing the absorption or the brain entry of various pharmacological agents [22].

In summary, we found that A-770041 could increase the sensitivity of drug-resistant osteosarcoma cells to various cytotoxic chemotherapeutic agents (doxorubicin, paclitaxel). These studies provided a proof of principle that A-770041 is active against osteosarcoma cell lines with known resistance to conventional anticancer agents, as well as primary tumor cells from osteosarcoma patients. Further in vivo research is warranted to understand the implication of A-770041 in overcoming drug resistance.

\section{Conclusions}

Kinases play an essential role in cancer cell growth, survival and drug resistance, and these enzymes are actively investigated by the pharmaceutical industry to create molecular therapies.

In this study, a cell-based screening assay using the MDR osteosarcoma cell line was used to screen a kinase specific inhibitor compound library and identify smallmolecule compounds capable of reversing MDR. We identified A-770041, a potent Src family kinase (Lck and Src) inhibitor, as one of the most effective MDR reversing agents when combined with doxorubicin or paclitaxel. Because osteosarcoma is characterized by frequent relapse that is associated with the development of MDR, these findings provide support for further development of A-770041 or its derivates as candidate inhibitors of MDR in osteosarcoma treatment.

\section{Additional file}

Additional file 1: Identification of 18 kinase inhibitors that reverse

drug resistance in osteosarcoma MDR cell lines.

\section{Abbreviations}

MDR: Multidrug resistance; Lck: Lymphocyte-specific protein tyrosine kinase; Src: Src kinase.

\section{Competing interests}

The authors declare that they have no competing interests.

\section{Authors' contributions}

Conceived and designed the experiments: ZD JZ. Performed the experiments: ZD JZ SY. Analyzed the data: ZD JZ SY JS EC GC YH YZ NSG FJH. Contributed reagents/materials/ analysis tools: ZD JZ HM FJH. Wrote the paper: ZD JZ SY JS EC GC DH HM YH YZ NSG FJH. All authors have read and approved the final manuscript.

\section{Acknowledgements}

This project was supported, in part, by a grant from Sarcoma Foundation of America (SFA), grants from the Gategno and Wechsler funds, and NIH U54 HG006097 (NSG and JZ). Support has also been provided by the Jennifer Hunter Yates Foundation and the Kenneth Stanton Fund.

\section{Author details}

${ }^{1}$ Center for Sarcoma and Connective Tissue Oncology, Massachusetts Genera Hospital, 100 Blossom St., Jackson 1115, Boston 02114, MA, USA. ${ }^{2}$ Cutaneous Biology Research Center, Massachusetts General Hospital, Boston 02114, MA, USA. ${ }^{3}$ Shanghai First People's Hospital, Shanghai Jiaotong University, 
Shanghai 200080, China. ${ }^{4}$ Department of Orthopedic Surgery, Liu Hua Qiao Hospital, Guangzhou 510010, China. ${ }^{5}$ Dana Farber Cancer Institute, Harvard Medical School, Boston, MA 02115, USA.

Received: 4 June 2014 Accepted: 16 September 2014

Published: 19 September 2014

\section{References}

1. Bielack SS, Marina N, Ferrari S, Helman LJ, Smeland S, Whelan JS, Reaman GH: Osteosarcoma: the same old drugs or more? J Clin Oncol 2008, 26(18):3102-3103. author reply 3104-3105.

2. Gill J, Ahluwalia MK, Geller D, Gorlick R: New targets and approaches in osteosarcoma. Pharmacol Ther 2013, 137(1):89-99.

3. Geller DS, Gorlick R: Osteosarcoma: a review of diagnosis, management, and treatment strategies. Clin Adv Hematol Oncol 2010, 8(10):705-718.

4. Chou AJ, Geller DS, Gorlick R: Therapy for osteosarcoma: where do we go from here? Paediatr Drugs 2008, 10(5):315-327.

5. Chou AJ, Gorlick R: Chemotherapy resistance in osteosarcoma: current challenges and future directions. Expert Rev Anticancer Ther 2006, 6(7):1075-1085.

6. Susa M, lyer AK, Ryu K, Choy E, Hornicek FJ, Mankin H, Milane L, Amiji MM, Duan Z: Inhibition of ABCB1 (MDR1) expression by an siRNA nanoparticulate delivery system to overcome drug resistance in osteosarcoma. PLoS One 2010, 5(5):e10764.

7. Kobayashi E, Iyer AK, Hornicek FJ, Amiji MM, Duan Z: Lipid-functionalized dextran nanosystems to overcome multidrug resistance in cancer: a pilot study. Clin Orthop Relat Res 2013, 471(3):915-925.

8. Brambilla D, Zamboni S, Federici C, Lugini L, Lozupone F, De Milito A, Cecchetti S, Cianfriglia M, Fais S: P-glycoprotein binds to ezrin at amino acid residues $149-242$ in the FERM domain and plays a key role in the multidrug resistance of human osteosarcoma. Int I Cancer 2012, 130(12):2824-2834

9. Cagliero E, Ferracini R, Morello E, Scotlandi K, Manara MC, Buracco P, Comandone A, Baroetto Parisi R, Baldini N: Reversal of multidrugresistance using Valspodar (PSC 833) and doxorubicin in osteosarcoma. Oncol Rep 2004, 12(5):1023-1031.

10. Pakos EE, loannidis JP: The association of P-glycoprotein with response to chemotherapy and clinical outcome in patients with osteosarcoma. A meta-analysis. Cancer 2003, 98(3):581-589.

11. Hotta T, Suzuki H, Nagai S, Yamamoto K, Imakiire A, Takada E, Itoh M, Mizuguchi J: Chemotherapeutic agents sensitize sarcoma cell lines to tumor necrosis factor-related apoptosis-inducing ligand-induced caspase- 8 activation, apoptosis and loss of mitochondrial membrane potential. J Orthop Res 2003, 21(5):949-957.

12. Zhao Y, Zhang CL, Zeng BF, Wu XS, Gao TT, Oda Y: Enhanced chemosensitivity of drug-resistant osteosarcoma cells by lentivirusmediated Bcl-2 silencing. Biochem Biophys Res Commun 2009, 390(3):642-647.

13. Mackeigan JP, Murphy LO, Blenis J: Sensitized RNAi screen of human kinases and phosphatases identifies new regulators of apoptosis and chemoresistance. Nat Cell Biol 2005, 7(6):591-600.

14. Du J, Bernasconi P, Clauser KR, Mani DR, Finn SP, Beroukhim R, Burns M, Julian B, Peng XP, Hieronymus H, Maglathlin RL, Lewis TA, Liau LM, Nghiemphu P, Mellinghoff IK, Louis DN, Loda M, Carr SA, Kung AL, Golub TR: Bead-based profiling of tyrosine kinase phosphorylation identifies SRC as a potential target for glioblastoma therapy. Nat Biotechnol 2009, 27(1):77-83.

15. Scotlandi K, Picci P: Targeting insulin-like growth factor 1 receptor in sarcomas. Curr Opin Oncol 2008, 20(4):419-427.

16. Wan $X$, Helman $L$ J: The biology behind mTOR inhibition in sarcoma. Oncologist 2007, 12(8):1007-1018.

17. Kim SY, Helman L: Strategies to explore new approaches in the investigation and treatment of osteosarcoma. Cancer Treat Res 2009, 152:517-528.

18. Hirai H, Sootome H, Nakatsuru Y, Miyama K, Taguchi S, Tsujioka K, Ueno Y, Hatch H, Majumder PK, Pan BS, Kotani H: MK-2206, an allosteric Akt inhibitor, enhances antitumor efficacy by standard chemotherapeutic agents or molecular targeted drugs in vitro and in vivo. Mol Cancer Ther 2010, 9(7):1956-1967.

19. Wang $Y H$, Xiong J, Wang SF, Yu Y, Wang B, Chen YX, Shi HF, Qiu Y: Lentivirus-mediated shRNA targeting insulin-like growth factor-1 receptor (IGF-1R) enhances chemosensitivity of osteosarcoma cells in vitro and in vivo. Mol Cell Biochem 2010, 341(1-2):225-233.

20. Duan Z, Choy E, Harmon D, Yang C, Ryu K, Schwab J, Mankin H, Hornicek FJ: Insulin-like growth factor-I receptor tyrosine kinase inhibitor cyclolignan picropodophyllin inhibits proliferation and induces apoptosis in multidrug resistant osteosarcoma cell lines. Mol Cancer Ther 2009, 8(8):2122-2130.

21. George JA, Chen T, Taylor CC: SRC tyrosine kinase and multidrug resistance protein-1 inhibitions act independently but cooperatively to restore paclitaxel sensitivity to paclitaxel-resistant ovarian cancer cells. Cancer Res 2005, 65(22):10381-10388.

22. Shukla S, Chen ZS, Ambudkar SV: Tyrosine kinase inhibitors as modulators of ABC transporter-mediated drug resistance. Drug Resist Updat 2012, 15(1-2):70-80.

23. Sodani K, Tiwari AK, Singh S, Patel A, Xiao ZJ, Chen JJ, Sun YL, Talele TT, Chen ZS: GW583340 and GW2974, human EGFR and HER-2 inhibitors, reverse $A B C G 2-$ and $A B C B 1$-mediated drug resistance. Biochem Pharmacol 2012, 83(12):1613-1622.

24. Liu Y, Gray NS: Rational design of inhibitors that bind to inactive kinase conformations. Nat Chem Biol 2006, 2(7):358-364.

25. Bamborough P, Morse MA, Ray KP: Targeting IKKbeta for the treatment of rheumatoid arthritis. Drug News Perspect 2010, 23(8):483-490.

26. Patricelli MP, Nomanbhoy TK, Wu J, Brown H, Zhou D, Zhang J, Jagannathan S, Aban A, Okerberg E, Herring C, Nordin B, Weissig H, Yang Q Lee JD, Gray NS, Kozarich JW: In situ kinase profiling reveals functionally relevant properties of native kinases. Chem Biol 2011, 18(6):699-710.

27. Weisberg E, Liu Q, Zhang X, Nelson E, Sattler M, Liu F, Nicolais M, Zhang J, Mitsiades C, Smith RW, Stone R, Galinsky I, Nonami A, Griffin JD, Gray N: Selective Akt inhibitors synergize with tyrosine kinase inhibitors and effectively override stroma-associated cytoprotection of mutant FLT3-positive AML cells. PLoS One 2013, 8(2):e56473.

28. Liu Y, Marks K, Cowley GS, Carretero J, Liu Q, Nieland TJ, Xu C, Cohoon TJ, Gao P, Zhang Y, Chen Z, Altabef AB, Tchaicha JH, Wang X, Choe S, Driggers EM, Zhang J, Bailey ST, Sharpless NE, Hayes DN, Patel NM, Janne PA, Bardeesy N, Engelman JA, Manning BD, Shaw RJ, Asara JM, Scully R, Kimmelman A, Byers LA, Gibbons DL, Wistuba II, Heymach JV, Kwiatkowski DJ, Kim WY, Kung AL, Gray NS, Root DE, Cantley LC, Wong KK: Metabolic and functional genomic studies identify deoxythymidylate Kinase as a target in LKB1 mutant lung cancer. Cancer Discov 2013, 3(8):870-879.

29. Lourda M, Trougakos IP, Gonos ES: Development of resistance to chemotherapeutic drugs in human osteosarcoma cell lines largely depends on up-regulation of Clusterin/Apolipoprotein J. Int J Cancer 2007, 120(3):611-622.

30. Duan Z, Ji D, Weinstein EJ, Liu X, Susa M, Choy E, Yang C, Mankin H, Hornicek FJ: Lentiviral shRNA screen of human kinases identifies PLK1 as a potential therapeutic target for osteosarcoma. Cancer Lett 2010, 293(2):220-229.

31. Burchat A, Borhani DW, Calderwood DJ, Hirst GC, Li B, Stachlewitz RF: Discovery of A-770041, a src-family selective orally active Ick inhibitor that prevents organ allograft rejection. Bioorg Med Chem Lett 2006, 16(1):118-122

32. Stachlewitz RF, Hart MA, Bettencourt B, Kebede T, Schwartz A, Ratnofsky SE, Calderwood DJ, Waegell WO, Hirst GC: A-770041, a novel and selective small-molecule inhibitor of Lck, prevents heart allograft rejection. $J$ Pharmacol Exp Ther 2005, 315(1):36-41.

33. Meyn MA 3rd, Smithgall TE: Small molecule inhibitors of Lck: the search for specificity within a kinase family. Mini Rev Med Chem 2008, 8(6):628-637.

34. Cantiani L, Manara MC, Zucchini C, De Sanctis P, Zuntini M, Valvassori L, Serra M, Olivero M, Di Renzo MF, Colombo MP, Picci P, Scotlandi K: Caveolin-1 reduces osteosarcoma metastases by inhibiting c-Src activity and met signaling. Cancer Res 2007, 67(16):7675-7685.

35. Shor AC, Keschman EA, Lee FY, Muro-Cacho C, Letson GD, Trent JC, Pledger WJ, Jove R: Dasatinib inhibits migration and invasion in diverse human sarcoma cell lines and induces apoptosis in bone sarcoma cells dependent on SRC kinase for survival. Cancer Res 2007, 67(6):2800-2808.

36. Patel A, Tiwari AK, Chufan EE, Sodani K, Anreddy N, Singh S, Ambudkar SV, Stephani R, Chen ZS: PD173074, a selective FGFR inhibitor, reverses $A B C B 1-m e d i a t e d$ drug resistance in cancer cells. Cancer Chemother Pharmacol 2013, 2013:2013.

37. Posthumadeboer J, van Egmond PW, Helder MN, de Menezes RX, Cleton-Jansen AM, Belien JA, Verheul HM, van Royen BJ, Kaspers GJ, van Beusechem VW: Targeting JNK-interacting-protein-1 (JIP1) sensitises osteosarcoma to doxorubicin. Oncotarget 2012, 3(10):1169-1181. 
38. Spina A, Sorvillo L, Chiosi E, Esposito A, Di Maiolo F, Sapio L, Caraglia M, Naviglio S: Synergistic cytotoxic effects of inorganic phosphate and chemotherapeutic drugs on human osteosarcoma cells. Oncol Rep 2013, 29(5):1689-1696.

39. Naviglio $\mathrm{S}$ : The possible use of inorganic phosphate in osteosarcoma therapy. Future Oncol 2013, 9(9):1249-1251.

40. Michels S, Trautmann M, Sievers E, Kindler D, Huss S, Renner M, Friedrichs N, Kirfel J, Steiner S, Endl E, Wurst P, Heukamp L, Penzel R, Larsson O, Kawai A, Tanaka S, Sonobe H, Schirmacher P, Mechtersheimer G, Wardelmann E, Büttner R, Hartmann W: SRC signaling is crucial in the growth of synovial sarcoma cells. Cancer Res 2013, 73(8):2518-2528.

41. Heiska L, Melikova M, Zhao F, Saotome I, McClatchey Al, Carpen O: Ezrin is key regulator of Src-induced malignant phenotype in three-dimensional environment. Oncogene 2011, 30(50):4953-4962.

42. Le XF, Bast RC Jr: Src family kinases and paclitaxel sensitivity. Cancer Biol Ther 2011, 12(4):260-269.

43. Kitazaki T, Oka M, Nakamura Y, Tsurutani J, Doi S, Yasunaga M, Takemura M, Yabuuchi H, Soda H, Kohno S: Gefitinib, an EGFR tyrosine kinase inhibitor, directly inhibits the function of P-glycoprotein in multidrug resistant cancer cells. Lung Cancer 2005, 49(3):337-343.

44. Tsai CM, Chiu CH, Chang KT, Chen JT, Lai CL, Chen YM, Hsiao SY: Gefitinib enhances cytotoxicities of antimicrotubule agents in non-small-cell lung cancer cells exhibiting no sensitizing epidermal growth factor receptor mutation. J Thorac Oncol 2012, 7(8):1218-1227.

doi:10.1186/1471-2407-14-681

Cite this article as: Duan et al: A-770041 reverses paclitaxel and doxorubicin resistance in osteosarcoma cells. BMC Cancer 2014 14:681.

\section{Submit your next manuscript to BioMed Central and take full advantage of:}

- Convenient online submission

- Thorough peer review

- No space constraints or color figure charges

- Immediate publication on acceptance

- Inclusion in PubMed, CAS, Scopus and Google Scholar

- Research which is freely available for redistribution 